either test, may not have selected their patients on the basis of these values. Therefore, the patients we studied might not be comparable with those examined by these authors. In addition, we measured VIIIVWF using formalin-treated and not freshly prepared washed platelets, although in the few cases in which VIIIVWF was also assayed on platelets obtained as described by Kazatchkine et al the values obtained did not differ from those reported in the table. Our data do not rule out the possibility that a low plasma VIIIVWF level, if present, might contribute to the bleeding tendency of some patients with CRF. They do, however, also imply that a selective defect of VIIIVWF is probably an uncommon finding in patients with CRF and abnormal bleeding time and platelet retention.

The practical implication of the results of Kazatchkine et al,? though not mentioned by them, is that factor VIII-rich preparations could be used in the management of the bleeding diathesis of patients with CRF undergoing haemodialysis. On the basis of our data, we would caution against any hasty generalising of such a therapeutic approach. Indeed, the cause of the bleeding tendency found in many patients with CRF is still to be established.

Judith Baggott, Anna Mancini, Paola Seminari, and Vincenzo De Ceglie helped in preparing the manuscript. This investigation was supported in part by the Associazione Bergamasca per lo Studio delle Malattie Renali.

Requests for reprints should be addressed to: Dr Giuseppe Remuzzi, Divisione di Nefrologia e Dialisi, Ospedali Riuniti di Bergamo, Bergamo, Italy.

\section{References}

${ }^{1}$ Salzman, E W, and Neri, L L, Thrombosis et Diathesis Haemorrhagica, $1966,15,84$.

2 Larsson, S O, Scandinavian fournal of Haematology, 1971, suppl No 15, p 1.

3 Rabiner, S F, Medical Clinics of North America, 1972, 56, 221.

4 Eknoyan, G, et al, New England fournal of Medicine, 1969, 280, 677.

${ }^{5}$ Horowitz, H I, Archives of Internal Medicine, 1970, 126, 823.

${ }^{6}$ Praga, C, et al, in Actualités Néphrologiques de l'Hôpital Necker, p 137. Paris, Flammarion, 1968.

${ }^{7}$ Kazatchkine, M, et al, British Medical fournal, 1976, 2, 612.

${ }^{8}$ Remuzzi, G, et al. Submitted for publication.

${ }^{9}$ Castaldi, P A, Rozenberg, N C, and Stewart, J H, Lancet, 1966, 2, 66.

${ }^{10}$ Bouma, B N, et al, Nature New Biology, 1972, 236, 104

11 Weiss, H J, New England fournal of Medicine, 1974, 290, 464.

12 Praga, C, Cortellaro, M, and Pogliani, E, in Platelet Function and Thrombosis. A review of Methods, ed P M Mannucci and S Gorini, p 149. New York, Plenum Press, 1972.

${ }^{13}$ Hellem, A J, Scandinavian fournal of Haematology, 1970, 7, 374.

14 de Gaetano, G, et al, Thrombosis Research, 1976, 8, 361.

15 Laurell, C B, Annals of Biochemistry and Experimental Medicine, 1966, 15, 45.

16 Italian Working Group, British fournal of Haematology, 1977, 35, 101

17 Weiss, H J, et al, fournal of Clinical Investigation, 1973, 52, 2708.

${ }^{18}$ Macfarlane, D E, et al, Thrombosis et Diathesis Haemorrhagica, 1975, 34, 306.

19 Macfarlane, D E, Thrombosis and Haemostasis, 1976, 36, 282.

${ }^{20}$ Olson, J D, et al, American fournal of Clinical Pathology, 1975, 63, 210.

${ }^{21}$ Holmberg, L, and Nilsson, I M, Scandinavian fournal of Haematology, $1974,12,221$.

${ }^{22}$ Ratnoff, O D, and Bennett, B, New England Fournal of Medicine, 1973, 289, 1182.

${ }^{23}$ Mannucci, P M, et al, fournal of Laboratory and Clinical Medicine, 1976, $\mathbf{8 8}, 662$.

(Accepted 30 May 1977)

\title{
Spina bifida and anencephaly: Are miscarriages a possible cause?
}

\author{
K M LAURENCE, C J ROBERTS
}

British Medical fournal, 1977, 2, 361-362

\section{Summary}

The marriage-to-conception interval in 151 pregnancies producing infants with anencephaly or spina bifida was not significantly different from that in 218 pregnancies resulting in normal infants. Significantly more miscarriages occurred before than after the birth of 285 infants with anencephaly or spina bifida, but in 133 controls no before-after difference was observed.

These observations seem to favour the idea that miscarriages are a manifestation rather than a cause of anencephaly and spina bifida.

\section{Introduction}

The hypothesis that anencephaly and spina bifida (ASB) might be due to an interaction between twin fetuses or between a fetus and residual trophoblastic material from a previous normal

Welsh National School of Medicine, Heath Park, Cardiff

K M LAURENCE, DSC, MRCP, professor of paediatric research, department of child health

C J ROBERTS, MD, PHD, senior lecturer, department of community medicine pregnancy was put forward by Clarke et al among others. They suggested that information from miscarriages might support such a hypothesis, and, combining the information from several investigations, including a large family study from South Wales," they found more miscarriages before than after an ASB pregnancy, but the interval between miscarriage and the next pregnancy was no higher in cases of ASB than in other pregnancies. They thought that the former finding supported their hypothesis while the latter did not.

We examined the information on miscarriages in a large number of women not included in the analyses of Clarke et al in the hope that it might throw further light on the subject.

\section{Patients and methods}

The obstetric histories of two series of women were reviewed. The first series consisted of 1087 women who attended the genetic advisory service in Cardiff between 1967 and 1976 for various problems. An accurate obstetric history was taken, which included details of all miscarriages. In respect of pregnancies resulting in either stillbirths or live births, the length of gestation or the date of the last menstrual period, the date of delivery, and any malformations present were recorded.

The second series comprised 867 women living in Glamorgan and Gwent who had a pregnancy resulting in an offspring with a major ASB malformation from January 1962 to December 1972 and who were subsequently visited and interviewed in their homes in 1968-74 as part of an investigation into possible causal factors. They included the mothers of all infants with ASB born within an area of about 20 
miles around Swansea and Caerphilly, these being the home bases of the two interviewers. Only a randomly selected proportion of those who were living further afield were visited and therefore included in this investigation. These patients had an accurate obstetric history taken including details of all their miscarriages. In respect of pregnancies resulting in stillbirths and live births, the length of gestation or the date of the last menstrual period, the date of delivery, and any malformations present were recorded.

The study of the interval between miscarriage and the beginning of the next pregnancy was carried out only when the interval could be estimated accurately to the nearest month by knowing the date of the miscarriage and the probable date of conception. Missed abortions were not included. In all, 100 suitable miscarriages where the subsequent pregnancy had resulted in a fetus with a major neural tube malformation and 110 where the subsequent pregnancy had ended in a normal fetus (as a control group) were extracted from the 867 obstetric histories of the women included in the spina bifida investigations. The corresponding numbers from the 1087 women who attended for genetic advice were 51 and 108. Fifty-nine miscarriages had to be excluded because of uncertainty about the time interval or the possibility of a "missed abortion."

To compare the number of miscarriages occurring immediately before and after a pregnancy which resulted in an infant with ASB and those occurring in control pregnancies only those obstetric histories where there was at least one recognised pregnancy before and one pregnancy after the index case were included. A total of 285 suitable pregnancies which ended in an infant with ASB were found among the patients who were part of the spina bifida aetiology investigation. A control group was selected from the 1087 who attended for genetic advice; only those who attended for counselling about a single gene defect, chromosome anomaly, multiple malformation, or some acquired condition were included. Those who attended for advice about ASB, repeated abortion, and infertility were specifically excluded. A total of 133 suitable pregnancies that satisfied these criteria were found.

\section{Results}

In both series there was no significant difference in the miscarriageto-conception interval between the index cases and controls. The mean interval for all groups was 10 to 13 months (table I).

There were significantly more miscarriages before a pregnancy resulting in an infant with ASB $(26 \%)$ than after $(14 \%)(\mathrm{P}<0.05)$.

TABLE I-Miscarriage-to-conception interval in ASB and control pregnancies

\begin{tabular}{|c|c|c|}
\hline \multirow{2}{*}{ Interval (months) } & \multicolumn{2}{|c|}{ Cumulative frequency (" $\left.{ }_{0}\right)$} \\
\hline & ASB pregnancies & Control pregnancies \\
\hline $\begin{array}{l}<3 \\
<6 \\
<12 \\
<24 \\
<36\end{array}$ & $\begin{array}{l}\text { First series } \\
(\mathrm{n}=51) \\
12 \\
32 \\
62 \\
79 \\
100\end{array}$ & $\begin{array}{c}(\mathrm{n}=108) \\
10 \\
33 \\
65 \\
82 \\
100\end{array}$ \\
\hline Mean \pm SD & $12 \cdot 7 \pm 10 \cdot 10$ & $11 \cdot 8 \pm 9 \cdot 8$ \\
\hline $\begin{array}{l}<3 \\
<6 \\
<12 \\
<24 \\
<36\end{array}$ & $\begin{array}{l}\text { Second series } \\
(\mathrm{n}=100) \\
13 \\
38 \\
62 \\
87 \\
100\end{array}$ & $\begin{array}{c}(\mathrm{n}=110) \\
20 \\
44 \\
66 \\
89 \\
100\end{array}$ \\
\hline Mean \pm SD & $10 \cdot 8 \pm 8 \cdot 9$ & $11 \cdot 9=9 \cdot 1$ \\
\hline
\end{tabular}

TABLE II-Miscarriages immediately before and after index pregnancies

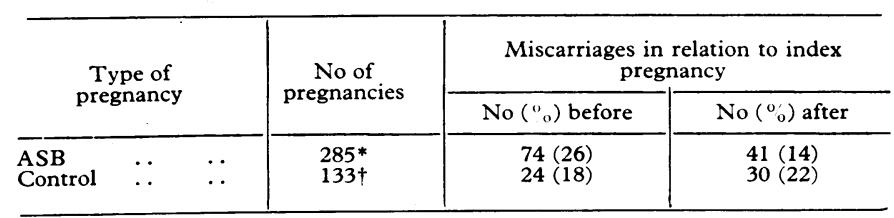

*From 867 obstetric histories. †From 393 obstetric histories.
There was no significant difference in the proportion of miscarriages before and after a normal pregnancy in the control group (table II).

\section{Discussion}

Our results confirm those of Clarke $e t$ al $^{1}$ that there are more miscarriages before than after a pregnancy that results in an infant with ASB. Our additional finding that this difference was not present among women giving birth to normal babies can be regarded as supporting the hypothesis that ASB might arise from an interaction between a fetus and residual trophoblastic material from a previous pregnancy. It might, however, also be regarded as a logical expectation of the hypothesis that the frequency of ASB is much higher than is usually supposed, the prevalence at birth tending to be much lower than the true incidence in early pregnancy because of a very high early mortality of affected embryos. ${ }^{3}$ In this case the observation of an increased abortion rate antedating the birth of infants with ASB (table II) may simply reflect the loss of malformed fetuses who also had an ASB. This explanation is simpler than the interactive hypothesis, and, unlike the latter, it is consonant with a growing body of evidence from human and animal studies. Ideally, however, both the hypotheses proffered would expect a higher frequency of miscarriages in the index group than in the control group, and this was not observed by Clarke et $a l^{1}$ or by ourselves.

But the confirmation of the latter expectation is complicated by the fact that the number of miscarriages reported will be related to the number of conceptions that occur. Women who have given birth to an infant with ASB are more likely, as a group, to take steps to prevent further conceptions, in which case the after-pregnancy frequency of miscarriage among the index group may not be a fair reflection of the miscarriage pattern that would emerge from a completely unprotected postcoital series. On balance therefore, the results seem to give slight support to both hypotheses but do not help to discriminate between them.

The confirmation in our study that the interval between miscarriage and the next pregnancy was no greater in the case of pregnancies resulting in an infant with ASB than in the control series does not support the interaction hypothesis. This inference is based on the not unreasonable assumption that the process of interaction requires some time to develop and is not instantaneous. The observation that the interval was no greaterfirst reported by Clarke et al and now confirmed in two separate series by us-suggests that the processes of miscarriage or its sequelae, or both, are not directly implicated in causing ASB.

Considered jointly, the observation of a greater frequency of miscarriages before than after an ASB pregnancy and the fact that the miscarriage to next conception interval appears to be unrelated to outcome seem to favour the notion that miscarriages are a manifestation rather than a cause of ASB. This being so, our findings and those of Clarke et al are perhaps more likely to reflect a high incidence of ASB followed by high embryonic mortality rate in such cases, as suggested by Roberts and Lowe, ${ }^{3}$ than an interaction between residual trophoblastic and normal fetal material leading to ASB, as proposed by Clarke et al. ${ }^{1}$

We wish to thank Dr Nansi James and Dr Mary Miller, who visited the mothers who took part in the investigation into the aetiology of neural tube malformations. That investigation was supported by grants from Action for the Crippled Child and Tenovus.

\section{References}

${ }^{1}$ Clarke, C, et al, British Medical fournal, 1975, 4, 743.

2 Carter, C O, David, P A, and Laurence, K M, fournal of Medical Genetics, $1968,5,81$.

${ }^{3}$ Roberts, C J, and Lowe, C R, Lancet, 1975, 1, 498. 